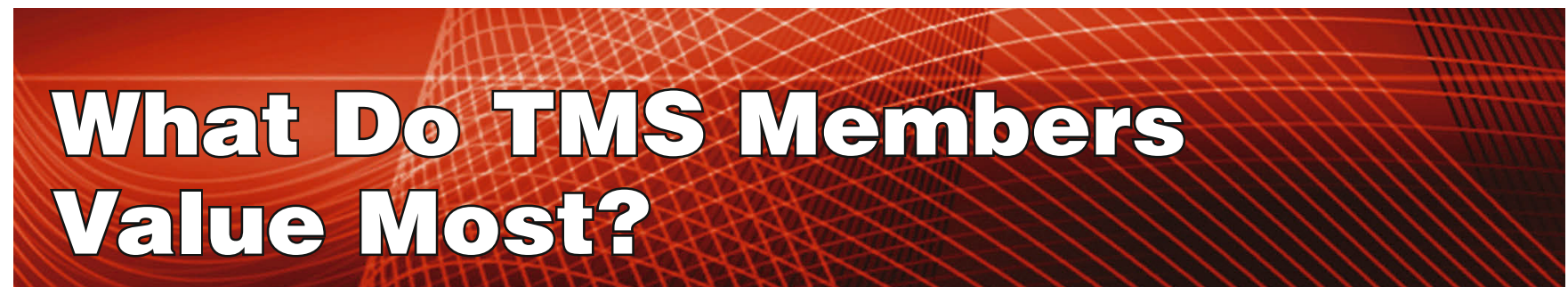

\title{
Kevin Hemker
}

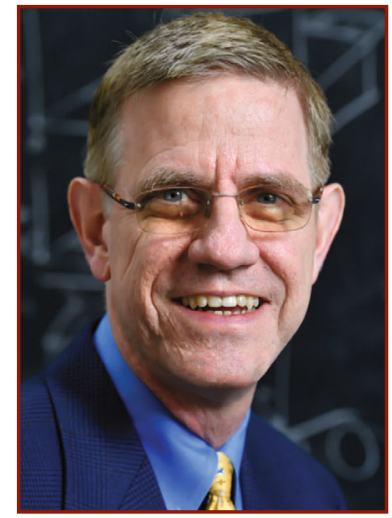

Kevin J. Hemker

"Personally, I find

the relationships

that l've built

with other TMS

members over

the years to be

the most valuable

benefit of my TMS

membership."

Think of all the benefits you receive as a TMS member. Now, of those benefits, try to identify the one that means the most to you - the thing that keeps you renewing your TMS membership year after year.

Do you have it? Good. Now let me see if I can guess your answer.

Is it attending TMS meetings? If so, I have good news for you. The year will open with the TMS 2019 Annual Meeting \& Exhibition (TMS2019), which will take place in San Antonio, Texas, March 10-14. A highlight of TMS2018 was our standingroom-only, all-conference plenary, and we are looking at generating that same level of excitement with this year's allconference plenary talk by Luana Iorio, General Manager, Materials \& Process Engineering, GE Aviation. A number of other learning and networking events are under development, in addition to more than 80 symposia, so whether you're coming to speak, to learn from your peers, to see old friends, or to make new ones, TMS2019 promises to be a can't-miss event.

The Materials Science \& Technology 2019 Technical Meeting and Exhibition (MS\&T19) provides a unique opportunity for TMS members to convene with colleagues in our sister societies. MS\&T will travel to Portland, Oregon, for the first time, from September 29 to October 3, 2019.

TMS also has a busy slate of specialty meetings planned for 2019. The 5th World Congress on Integrated Computational Materials Engineering (ICME 2019) - a signature event for the Society-will take place July 21-25, 2019 in Indianapolis, Indiana. Then it's on to Dearborn, Michigan, for the 11th International Conference on Porous Metals and Metallic Foams (MetFoam 2019), which TMS will host for the first time, August 20-23, 2019. A returning event for TMS will be the 2019 Liquid Metal Processing and Casting Conference (LMPC 2019), set for September 15-18, 2019 in Birmingham, United Kingdom. A brand new TMS meeting will also debut in 2019- The World Congress on High Entropy Alloys (HEA 2019), November 17-20, 2019 in Seattle, Washington. TMS members receive discounted registration rates for all of these events, so mark your calendars.

If you cannot make it to all the conferences, perhaps reading TMS journals is your favorite TMS-related activity? If so, I have good news here, too. In July, TMS received a report that showed that the impact factors of our publications are continuing to trend upward. $J O M$, the TMS member journal, rose from 1.860 in 2016 to 2.145 in 2017. Metallurgical and Materials Transactions $A$ and $B$ also enjoyed impact factor increases this year. You can access all of these publications for free-along with Integrating Materials and Manufacturing Innovation, Journal of Electronic Materials, Journal of Sustainable Metallurgy, and 20 additional Springer journals - with your TMS membership, just by logging in to the Journals section of the TMS website at www.tms.org/journals.

Maybe your most valued TMS benefit is the chance to give back to your community while establishing connections in your field? There are a number of ways to contribute through TMS. New this year is the chance to volunteer with Materials Explorers, ${ }^{\mathrm{TM}}$ an outreach program for early high school students that makes STEM concepts come to life by connecting them with popular culture and everyday applications. Materials 
Explorers $^{\mathrm{TM}}$ engages students in hands-on learning and relies on willing volunteers to help present the program in local schools. Only TMS members can participate as volunteers.

There are many other ways to contribute, too. If you want to start learning the ropes of symposia organizing, you can volunteer as a session chair at TMS2019-remember that you don't have to be a presenter to be an active participant in the conference. If you want to gain more experience in the publishing realm, offer to serve as a reviewer for a TMS journal. If you're fluent in several languages, volunteer to serve as a translator to greet international attendees at the start of TMS conferences and help them to feel more at home.

You can take a variety of pathways in using your TMS membership as a springboard to serving your community. Learn about additional volunteer opportunities with the Society at www.tms .org/volunteer.

Many of the volunteer opportunities mentioned above begin with membership on a technical committee. The

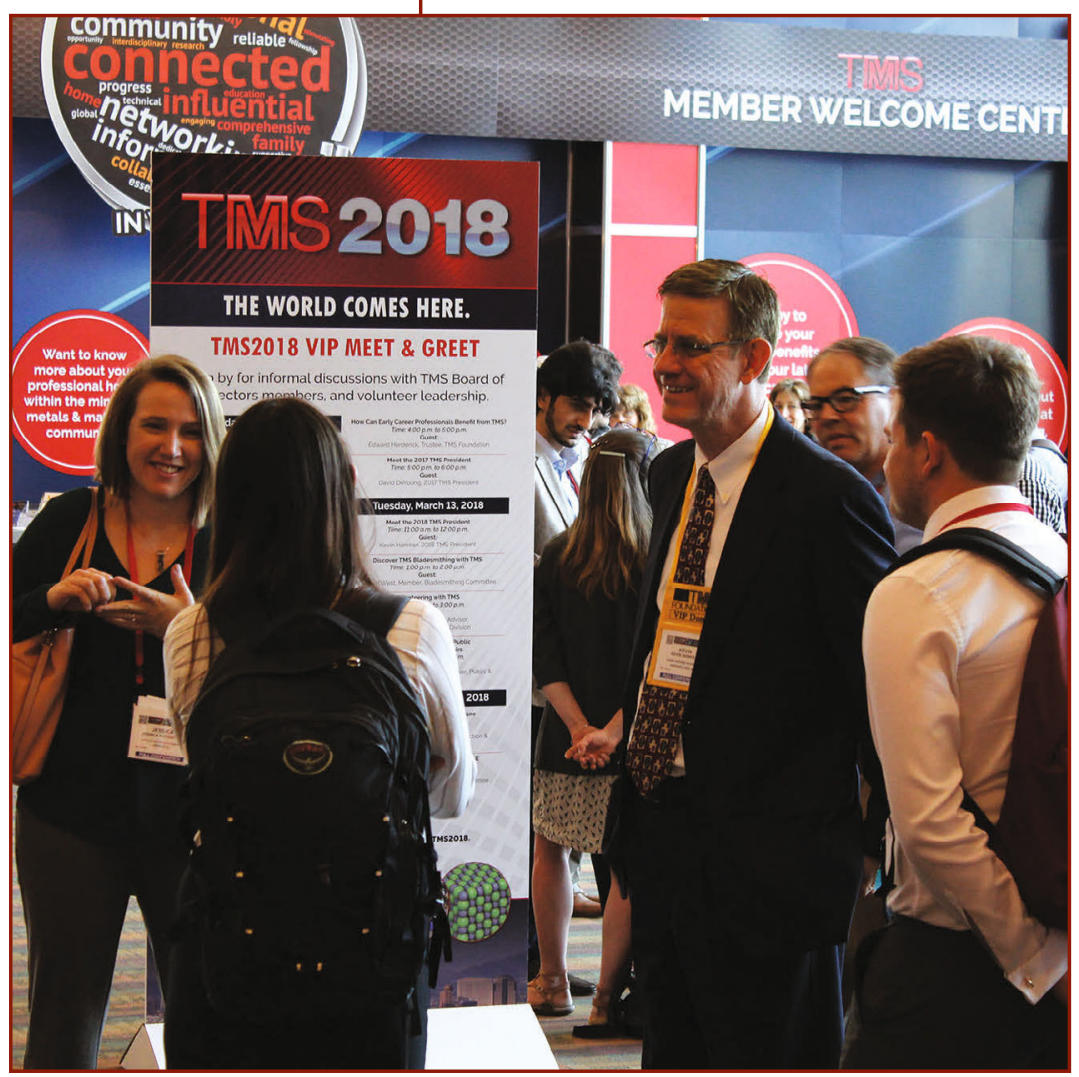

2018 TMS President Kevin Hemker talks with attendees at the TMS 2018 Annual Meeting \& Exhibition as part of the TMS2018 VIP Meet \& Greet event. programming that you see at meetings, the topics you see covered in JOM, and many other Society activities begin at the committee level, where dedicated volunteers first propose ideas and then bring them to life. Technical committees are open to all TMS members to join, and I'd like you to consider this a personal invitation to select the committee that best aligns with your technical interests and ask to have your name added to the committee roster. A full list of committees can be found at www.tms.org/Committees.

Personally, I find the relationships that I've built with other TMS members over the years to be the most valuable benefit of my TMS membership. It's this familial aspect of the Society - the feeling that a TMS meeting is more like a professional family reunion than a business gatheringthat keeps me coming back, year after year and engaged as a life-time TMS member.

No matter what keeps you coming back to TMS, I encourage you to take a few moments today to renew your membership for 2019-both to remain a valued part of our community and so that you won't miss out on TMS's plans for the coming years.

The TMS Board of Directors is currently working on a new strategic plan to steer the success of the Society into the future, with a focus on the elements of TMS that mean the most to its members. You can renew your membership today for one, three, five years, or a lifetime at members.tms.org.

Now that you've had time to reflect on the value of your TMS membership, consider sharing your insights about your favorite benefits with a colleague who might not be aware of our full range of offerings. Our Society is built on a foundation of engaged members and volunteers. A broader and more diverse community of members can only serve to strengthen the Society and the benefit that we, as members, receive from it. Don't be afraid to spread the word. An introduction to the types of membership we offer and the benefits new members receive can be found at www.tms.org/Membership.

I look forward to another successful year of membership with you in The Minerals, Metals \& Materials Society!

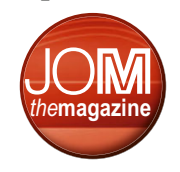

